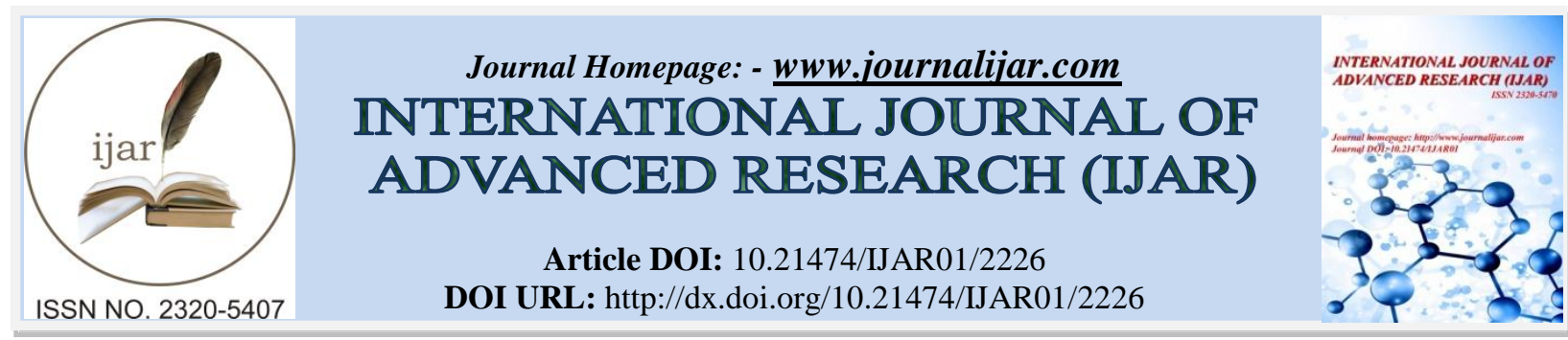

RESEARCH ARTICLE

\title{
DEVELOPMENT AND VALIDATION OF RP-HPLC METHOD FOR SIMULTANEOUS ESTIMATION OF RANITIDINE HYDROCHLORIDE AND DOMPERIDONE IN COMBINED DOSAGE FORM
}

\author{
${ }^{*}$ Varsha N. More ${ }^{1}$, Savita J. Tauro ${ }^{2}$ and Pravin B. Patil ${ }^{3}$ \\ 1. Lecturer; St. John Institute of Pharmacy \& Research, Palghar, Mumbai 401404. \\ 2. Principal; St. John Institute of Pharmacy \& Research, Palghar, Mumbai 401404. \\ 3. Quality Assurance Officer; Impulse Pharma Pvt. Ltd., Boisar, Mumbai 401506.
}

\section{Manuscript Info}

\section{Manuscript History}

Received: 28 September 2016

Final Accepted: 30 October 2016

Published: November 2016

Key words:-

RP-HPLC, Ranitidine Hydrochloride, Domperidone, Combined dosage form, Mobile phase, Retention time, Quality control.

\begin{abstract}
Analysis is important in every product but it is vital in medicines as it involves life. The assurance of quality is achieved through analysis of the drug product. Now days, the pharmaceutical dosage form of combinational drugs are very much useful in multiple therapies, rather than the use of single drug formulation because of multiple action, fewer side effects and quicker relief. Present work is an attempt to develop an accurate, sensitive, reliable and simple RP-HPLC technique for the simultaneous estimation of the drugs Ranitidine Hydrochloride and Domperidone in combined dosage form (Tablet formulation). RPHPLC method was developed and validated as per ICH guidelines by using Methanol:Water (55:45v/v) pH 3 as mobile phase. Retention time of Ranitidine Hydrochloride and Domperidone were found to be 7.865 min and 2.836 min respectively. The wavelength used was $280 \mathrm{~nm}$ and flow rate was $1.0 \mathrm{ml} / \mathrm{min}$. The method was found to be simple, accurate, precise, economical and reproducible. So, the proposed method can be used for the routine quality control analysis of Ranitidine Hydrochloride and Domperidone in tablet formulations.
\end{abstract}

Copy Right, IJAR, 2016,. All rights reserved.

\section{Introduction:-}

High Performance Liquid Chromatography (HPLC) is a separation technique involving mass transfer between stationary and mobile phase. HPLC is high resolution, high pressure and high speed liquid chromatography. It has several times resolving power than open column liquid chromatography hence it is used for speedy resolution of complex mixture, separation and determination of species in a variety of organic, inorganic and biological materials ${ }^{1}$.

\section{Advantages of HPLC:-}

Most of the drugs in multi-component dosage forms can be analyzed by HPLC method because of the several advantages like rapidity, specificity, accuracy, precision and ease of automation in this method. HPLC method eliminates tedious extraction isolation procedures. Some of the advantages are-

1) Speed (Analysis can be accomplished in 20 minutes or less).

2) There is ease of sample preparation and sample introduction.

3) Greater sensitivity (Various detectors can be employed).

4) Improved resolution (Wide variety of stationary phases). 
5) Easy sample recovery, handling \& maintenance.

6) It offers advantage over gas chromatography in analysis of many polar, ionic substances, high molecular weight substances, metabolic products and thermolabile as well as nonvolatile substances.

7) Instrumentation tends itself to automation and quantitation (Less time and less labour).

8) Suitable for preparative liquid chromatography on a much larger scale ${ }^{\mathbf{2 , 3}}$.

\section{HPLC Theories:-}

Two Main Aspects Comprise HPLC Theory -

Kinetic aspect of chromatographic zone migration is responsible for the band broadning and thermodynamic aspects are responsible for the analyte retention in the column. The process of chromatographic zone dispersion in the column usually called efficiency is one of the important descriptor of a chromatographic system ${ }^{4}$.

\section{System Suitability Parameters -}

A system suitability test is an integral part of gas and liquid chromatographic method. They are used to verify that the resolution and reproducibility of the chromatographic system are adequate for the analysis to be done. The test is based on concept that the equipment, electronic, analytical operation and sample to be analyzed constitute an integral system that can be evaluated as such. It is the verification of the system to ensure system performance before or during the analysis. Parameter such as plate count, tailing factor, reproducibility and resolution are determined and compared against the specification set for the method. The area under curve (AUC) of five replicate injections should not be more than $2 \%$ of relative standard deviation (RSD). The parameters that are affected by the changes in chromatographic conditions are-,
a) Retention time (Rt)
b) Theoretical plates (N)
c) Resolution (Rs)
d) Tailing factor (T)
e) Capacity factor (k)
f) Selectivity $(\alpha)$
g) Peak asymmetry

\section{Total Retention Time -}

It is the time, which is needed by a sample component to migrate from column inlet (sample injection) to the column end (detector). It varies with flow rate of mobile phase, temperature and column dimensions.

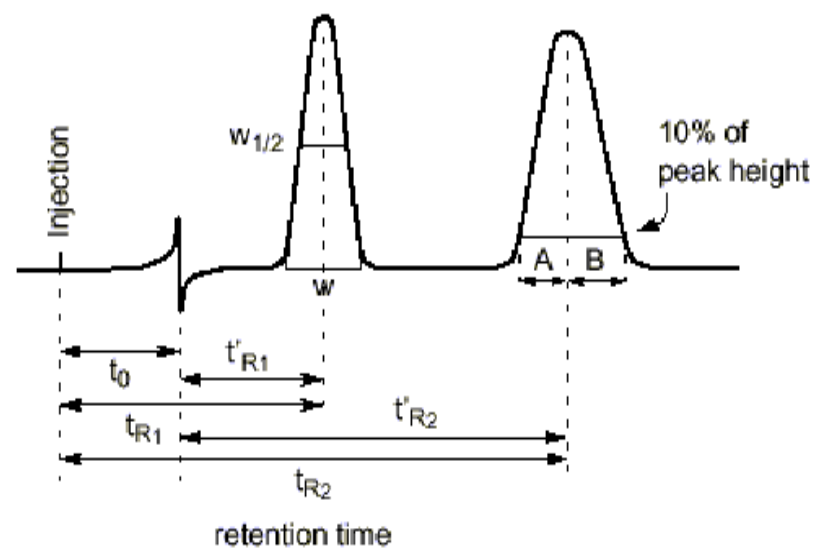

Fig.1:- Fundamental Parameters of Chromatography

\section{Retention Time (Rt) -}

Retention Time is the time of elution of peak of maximum after injection of compound. The net retention time ( $t$ 'R1 or t'R2) is the difference between total retention time and dead time i.e. the time, the sample component remains in the stationary phase. 


\section{Theoretical Plates (N) -}

It is also called as column efficiency. A column can be considered as being made of large number of theoretical plates where distribution of sample between liquid-liquid or solid-solid phase occurs. The number of theoretical plates in column is given by the relationship,

$\mathrm{N}=16(\mathrm{t} / \mathrm{w})^{2}-----------(1)$

Where $t$ is the retention time and $w$ is the width at the base of the peak. The height equivalent to a theoretical plate $h$ (HETP), L is the length, in which the chromatographic equilibrium between mobile and stationary phase is established. Since a large number of theoretical plates are desired, $\mathrm{h}$ should be as small as possible. The value of $\mathrm{h}$ is a criterion for the quality of a column values depend on the particle size, the flow velocity, the mobile phase (viscosity) and especially on the quality of the packing.

$\operatorname{HETP}(\mathrm{h})=\mathrm{L} / \mathrm{N}$

$\mathrm{L}=$ length of column

Theoretical Plates should be more than 2000.

\section{Resolution (R) -}

It is a function of column efficiency and is specified to ensure that closely eluting compounds are resolved from each other to establish the general resolving power of the system.

\section{Tailing Factor $(T)$ -}

It is the measure of peak symmetry, it is unity for perfectly symmetrical peaks and its value increases as tailing become more pronounced.

\section{Capacity Factor (k') -}

It is the ability of solute to interact with stationary phase and mobile phase.

\section{Selectivity (a) -}

Also known as separation factor, it is a measure of peak spacing.

\section{Quantitative Analysis in HPLC ${ }^{7,8}$ :-}

Two methods are generally used for quantitative analysis. They are external standard method and internal standard method.

\section{External Standard Method -}

The external standard method involves the use of a single standard or up to three solutions. The peak area or the height of the sample and the standard used are compared directly. One can also use the slope of the calibration curve based on standard that contain known concentrations of the compound of interest.

\section{Internal Standard Method -}

A widely used technique of quantitation involves addition of an internal standard to compensate for various analytical errors. In this approach, a known compound of a fixed concentration is added to the known amount of samples to give separate peaks in the chromatograms to compensate for the losses of the compounds of interest during sample pre-treatment steps. Any loss of the component of interest will be accompanied by the loss of an equivalent fraction of the internal standard. The accuracy of this approach obviously dependence on the structural equivalence of the compounds of interest and the internal standard.

\section{The Requirements for an Internal Standard are -}

1) It must have a completely resolved peak with no interferences.

2) It must elute close to the compound of interest.

3) It must behave equivalent to the compound of interest for analysis like pretreatment, derivative formations, etc.

4) It must be added at a concentration that will produce a peak area or peak height ratio of about unity with the compound.

5) It must not be present in the original sample.

6) It must be stable, unreactive with sample components, column packing and the mobile phase.

7) It is desirable that this compound is commercially available in high purity.

8) Internal standard should be added to the sample prior to sample preparation procedure and homogenized with it. To recalculate the concentration of a sample component in the original sample, we have to demonstrate first the response factor. 
Steps Involved in Quantitative Analysis ${ }^{8,9,10}$ :-

1) Sampling and Sample Preparation -

The sample should be homogeneous. It should be completely soluble and the solvent used to dissolve the sample should be initial mobile phase or any solvent miscible with mobile phase.

2) Chromatographic Separation -

After achieving a resolution with optimized solvent system, to obtain reproducible results following criteria must be satisfied.

a) Monitoring flow rate.

b) Keeping the solvent composition intact.

c) Solvent system must be covered before storage.

d) Monitoring column temperature.

3) Detection -

The response obtained from a given detector will vary according to the nature of solute molecule. With a UV detector the response is related to the both concentration and molecular extinction coefficient of the component at the wavelength of detection.

4) Measurement and Calibration -

The various approaches used for quantitative analysis -

Peak Height Method -

Peak height measurements represent a simple, satisfactory method for calculating detector response in the absence of mechanical or electronic signal integrators. In practice, a baseline is drawn from the leading edge of the chromatography peak to the tailing edge. The vertical distance from the peak apex to the predetermined baseline represents the peak height. For quantitative purpose -

a) The peak of interest must be symmetrical.

b) All parameters that affect peak width must be held constant.

Peak Area Method -

Computing electronic integrators are the simplest and most popular method for the determination of chromatographic peak areas. Quantitative measurements based on peak area can be performed by several methods.

\section{Systematic Steps for a Method Development in HPLC:-}

Choose a HPLC method and column that suits for the drug to be analyzed. Make two or more trials, to find out the separation magnitude on solvent strength and select mobile phase with respect to solvent strength. If separation from step 2 is not satisfactory, change solvent strength, $\mathrm{pH}$, additives etc. or try another HPLC method. Selectivity Vs mobile phase composition is adjudicated to exploit its separation potential for sample. Further improvement can be done by systematic variability in change of column, temperature etc. The chemical composition of the sample compound plays an important role in the method development. Hence, knowledge about the chemical structure, molecular weight, $\mathrm{pKa}$ and acidic or basic nature of the compound is beneficial ${ }^{\mathbf{1 1}}$.

\section{Method Development in HPLC ${ }^{12}$ :-}

In developing HPLC method for the quantitative analysis of multi-component formulation the following general requirements should be fulfilled -

1) The identity of the component to be analyzed should be established.

2) Separation of specific components should be achieved.

3) Sample preparation should be reproducible.

4) Standard of known purity should be available and accuracy will be directly related to the degree of purity of standards used in determination.

5) A stationary phase that separates the component in reproducible manner.

6) Sample application or injection should be reproducible.

Criteria for Selecting Proper HPLC Method ${ }^{13}$ :-

It is based on nature of the sample i.e. regular and special. Regular samples are typical mixtures of small molecules $(<2000 \mathrm{Da})$ that can be separated, using more or less standardized conditions. Regular samples can further classified into neutral or ionic. Ionic samples include acids, bases, amphoteric compounds and organic salts (ionized strong acids or bases). In neutral samples, generally buffers or additives are not required in mobile phase while acidic or basic compounds need addition of buffer to mobile phase. For basic or cationic samples, reversed phase columns are recommended and amine additives for mobile phase may be beneficial. In some cases, reverse phase conditions provide insufficient sample retention, suggesting use of either ion-pair or normal phase HPLC. Alternatively, the 
sample may be strongly retained with $100 \%$ acetonitrile as mobile phase, suggesting use of non-aqueous reversedphase (NARP) or normal- phase HPLC methods.

\section{Reverse Phase Chromatography (RPC):-}

It is the first choice for samples as it is convenient and rugged than other forms of liquid chromatography and is more likely to results in satisfactory final separation. Columns used in RPC are efficient, stable and reproducible. Detection is easier in RPC (especially UV detectors) because of the solvents used. Organic compounds have limited solubility in the aqueous mobile phase, this is not practical limitation because only small amount (Nanogram or microgram) of sample are usually injected.

\section{Separation by RPC -}

It is similar to the extraction of different compounds from water into an organic solvent. The column (typically, C8 or $\mathrm{C} 18$ bonded phase) is less polar than the water-organic mobile phase. Sample molecules partitions between the polar mobile phase and non-polar C8 or C18 stationary phase and more hydrophobic (non-polar) compounds are retained more strongly. Hydrophilic (polar) compounds are less strongly held and elute from column first, more hydrophobic (Non-polar) compounds elutes last. Compound of intermediate polarity elute in the middle of the chromatogram.

\section{Applications of Reversed -Phase Chromatography -}

1) Reversed-Phase Chromatography is the most popular mode for the separation of low molecular weight $(<3000)$, neutral species that are soluble in water or other polar solvents.

2) It is widely used in the pharmaceutical industry for separation of species such as steroids, vitamins, and betablockers.

3) It is also used in clinical laboratories for the analysis of catecholamines.

4) In the chemical industry for analysis of polymer additives.

5) In the environmental area for analysis of pesticides and herbicides.

6) In the analysis of food and beverage industry for analysis of carbohydrates, sweeteners, and food additives ${ }^{\mathbf{1 4 , 1 5}}$.

\section{Choice of Buffers ${ }^{16}:-$}

In acidic analytes, buffer $\mathrm{pH} 2$ units lower than $\mathrm{pKa}$ gives non dissociated species. The Buffer pH 2 units higher than $\mathrm{pKa}$ gives ionized species (anions). In basic analytes, buffer $\mathrm{pH} 2$ units higher than $\mathrm{pKa}$ gives non dissociated species. Buffer $\mathrm{pH} 2$ units lower than $\mathrm{pKa}$ gives ionized species (cations). Buffer solutions must be filtered after preparation. The selection of particulars of buffers depends on, Buffer capacity, UV- absorbance and other properties like solubility, interaction with the sample and column volatility, corrosion of HPLC system etc.

\section{Preferred Buffer ${ }^{17}:-$}

$\mathrm{C} 8$ or $\mathrm{C} 18$ bonded silica based columns are less stable outside the $\mathrm{pH}$ range 2-8. Therefore, buffer should be able to control $\mathrm{pH}$ between 2-8. Phosphate buffer should be used for controlling the $\mathrm{pH}$ in the range of 2.1-3.1 or 6.2-8.2. Acetate is an accepted choice for $\mathrm{pH} 3.8-5.8$ and phosphate plus acetate in combination can control $\mathrm{pH}$ reasonably all over the range 2-8. (Silica columns are less stable with phosphate buffers in the pH 6.2-8.2 and 11.3 -13.3 ranges). Citrate has the advantages that a single buffer can be used to explore a wide range in $\mathrm{pH} 2.1-6.4$, but it has disadvantage that claim to attack stainless steel.

\section{Selection of Suitable Detector:-}

Detector is an eye of HPLC system and measures compounds after their separation on the column. There are basically two types of detectors- the bulk property detectors and solute property detectors. Detectors, in order of their popularity are UV, fluorescent, conductivity, polarimeter and refractive index detectors. UV detector is the first choice because of its convenience and applicability in case of most of the samples. The latest version of equipments is available with photo diode- array detectors (PDA or DAD).

\section{Selection of Mobile Phase:-}

Reversed phase bonded packing, when used in conjunction with highly polar solvents approach is ideal and is an universal system for liquid chromatography. Mobile phase may be either single liquid or combination of liquids, which are compatible with sample, column and instrument. 


\section{Analytical Method Validation:-}

The efficacy and safety of a medicinal product can only be assured by analytical monitoring of its quality. Therefore the overall purity of a medicine must therefore be assessed throughout its storage, distribution and use. This objective can possibly be achieved if the specifications to be applied are based on a validated procedure which can demonstrate the relationship in quality between the substance under examination and that initially subjected to pharmaceutical, toxicological and pharmacological evaluation. The sound quality control will always depend on the use of valid analytical procedure. Method validation is the process of documenting or proving that an analytical method provides analytical data acceptable for the intended use. The validation is absolutely essential whether the procedure is intended to be applied within a manufacturing company, within a government control laboratory or proposed to be included in pharmacopoeia. Validation of analytical method is the process that establishes by laboratory studies, that the performance characteristics of the method meet the requirements for the indented analytical applications ${ }^{\mathbf{1 8 , 1 9}}$.

According to the ICH Guidelines Published for Method Validation Following Steps will be Considered ${ }^{19}$, 20,21,22,23.

1) Specificity or Selectivity

2) Accuracy

3) Linearity

4) Precision

5) Limit of Detection

6) Quantitation Limit

7) Robustness

8) Range

\section{Validation of Analytical Method:-}

In setting a new analytical method, the following points should be considered as per ICH guideline.

\section{Analytical Procedure -}

The analytical procedure refers to the way of performing the analysis. It should describe in detail the step necessary to perform each analytical test. This may include but is not limited to the reference standard and the reagents preparation, use of apparatus, generation of calibration curve, use of the formulae for the calculation etc.

\section{Parameters for Method Validation:-}

\section{1) Specificity or Selectivity -}

Specificity is an ability to assess unequivocally an analyte in the presence of components that may be expected to be present, such as impurities, degradants, matrix etc. The analytical response of an analyte in the presence of potential sample components is compared with the response of a solution containing only an analyte.

\section{2) Accuracy -}

The accuracy of an analytical procedure expresses the closeness of an agreement between the value, which is accepted either as a conventional true value or an accepted reference value and the value found. This is sometimes termed as trueness. It can be determined by applying the procedure to the quantitatively prepared sample of materials to be analyzed. Such sample also include to which analytes have been added in quantities both above and below the expected range (10\% above or below) of validation.

\section{3) Linearity -}

The linearity of an analytical method is its ability to elicit test results that are directly or by well defined mathematical transformation, proportional to the concentration of analytes in the sample within a given range. Linearity should be evaluated by inspection of a plot of signals as a function of analyte concentration or content. The study should be performed using standard solution at five concentration levels, in the range of 50 to $150 \%$ of the target analyte concentration. Each standard should be measured at least three times. An $r$ value of $>0.998$ is considered as evidence of acceptable fit of the data to the regression line.

\section{4) Precision -}

The precision of analytical procedure expresses closeness of agreement (degree of scatter) between a series of measurements obtained from multiple sample of the same homogenous sample under prescribed conditions. 


\section{5) Limit of Detection -}

The detection limit of an individual analytical procedure is the lowest amount of an analyte in a sample, which can be detected but not necessarily quantities as an exact value. The detection limit is expressed as the concentration of analyte (e.g. percentage, parts per billion) in the sample.

6) Quantitation Limit -

The quantitation limit of an individual analytical procedure is the lowest amount of analyte in a sample, which can be quantitatively determined with suitable precision and accuracy. Some approaches listed below may be acceptable. The quantitation limit is expressed as the concentration of analyte (e.g. percentage, parts per billion) in the sample.

\section{7) Robustness -}

The robustness of an analytical procedure is a measure of its capacity to remain unaffected by small, but deliberate variations in method parameters ( $\mathrm{pH}$ in a mobile phase, Mobile phase composition, Different columns, Temperature, Flow rate) and provides an indication of its reliability during normal usage.

\section{8) Range -}

The range of an analytical procedure is an interval between the upper and lower concentration of analyte in the sample for which it has been demonstrated that the analytical procedure is of precision, accuracy and linearity.

\section{Purpose of Validation:-}

1) Enable the scientists to communicate scientifically and effectively on technical matter.

2) Setting the standards of evaluation procedures for checking compliance and taking remedial action.

3) Economic: reduction in cost associated with process sampling and testing.

4) As quality of the product cannot always be assured by routine quality control because of testing of statistically insignificant number of samples.

5) Retrospective validation is useful for trend comparison of results compliance to CGMP/CGLP.

6) Closure interaction with Pharmacopoeial forum to address analytical problems.

\section{Materials and Methods:-}

A) Materials

1) Ranitidine Hydrochloride IP

Supplied by - Flemingo Pharma LTD, Mumbai.

Quantity - 20.0 gm

Purity (Assay) - $99.58 \%$

2) Domperidone IP

Supplied by - Flemingo Pharma LTD, Mumbai.

Quantity - 20.0 gm

Purity (Assay) - 99.47\%

The marketed preparation was purchased from the local market and is referred here after in this thesis by the name as such.

\section{3) Marketed Formulation Available}

Brand Name- ACITRO-D

Manufactured By- INTACTO-DEHRADUN

Composition- Ranitidine Hydrochloride IP

Domperidone IP ...................... (10 mg)

\section{Instrument -}

1) HPLC

a) Model - Schimadzu Prominence, KYOTO-Japan

LC-20AD

CAT NO.-228-45041-91

Serial No.-L 20304928116 SL

b) Binary Gradient

c) Degasser - Membrane degasser and ultrasonicator

d) Injector - Rheodyne injector with $20 \mu 1$ loop

e) Detector - Photo Diode Array detector SPD-M 20 A

f) Column -Thermo Scientific BDS - HYPERSIL C18 ( 250 x $4.6 \mathrm{~mm}$ i.d, $5 \mu$ particle size). 


\section{B) Method}

1) Selection of Analytical Wavelength -

By appropriate dilution of each standard stock solution with mobile phase, various concentrations of Ranitidine Hydrochloride and Domperidone were prepared separately. Each solution was scanned in between the range of 200 $\mathrm{nm}$ to $400 \mathrm{~nm}$ and their spectra were overlaid. The wavelength selected for the analysis was $280 \mathrm{~nm}$ which both the drugs showed significant absorbance. The overlain UV spectra of Ranitidine Hydrochloride and Domperidone in the mobile phase are as shown in figure below.

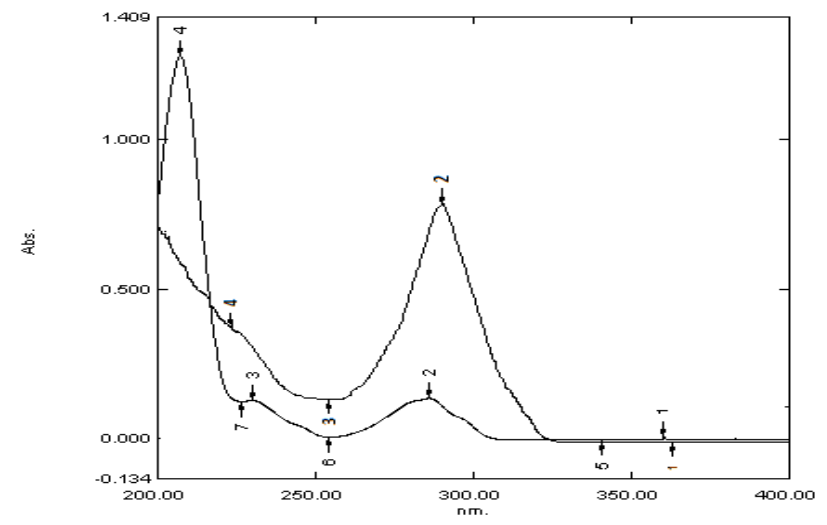

Fig. 2:- Overlain Spectra of Ranitidine Hydrochloride and Domperidone

\section{2) Calibration of Ranitidine Hydrochloride and Domperidone -}

Take $50 \mathrm{mg}$ of Ranitidine Hydrochloride \& $50 \mathrm{mg}$ of Domperidone separately in 50ml volumetric flask which was then dissolved in $50 \mathrm{ml}$ mobile phase with shaking. Take $5 \mathrm{ml}$ from this solution and dilute it up to $50 \mathrm{ml}$ with mobile phase. This becomes stock solution of $100 \mu \mathrm{g} / \mathrm{ml}$. Then it was sonicated. Suitable dilutions are made from the standard stock solutions. The linearity of the relationship between peak area and concentration was determined by analyzing five working standards over the concentration range of 50,100,150,200 and $250 \mu \mathrm{g} / \mathrm{ml}$ for Ranitidine \& $5,10,15,20$ and $25 \mu \mathrm{g} / \mathrm{ml}$ for Domperidone. Hence the peak areas were recorded against concentration \& graph of concentration Vs peak area was plotted.

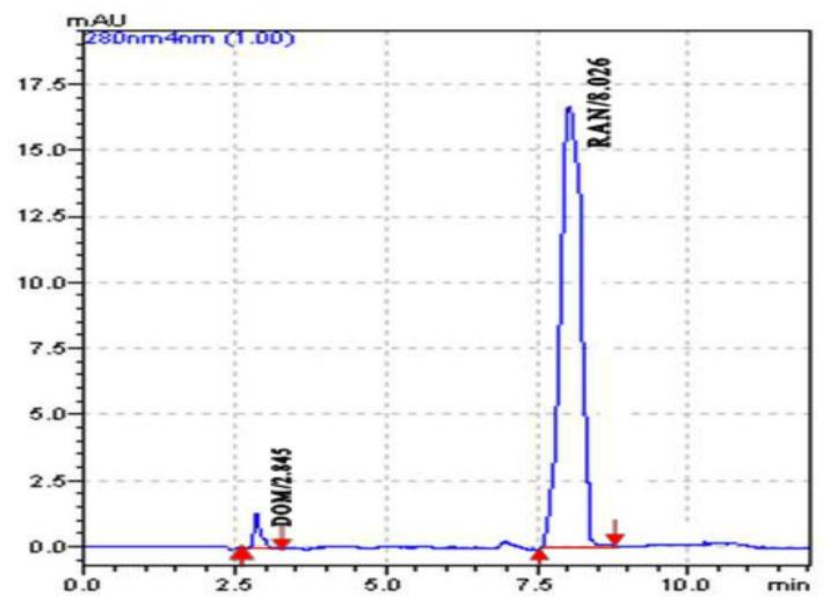

Fig. 3:- Chromatogram of Working Standard of Mixture of Domperidone $(5 \mu \mathrm{g} / \mathrm{ml})$ and Ranitidine Hydrochloride $(50 \mu \mathrm{g} / \mathrm{ml})$ 


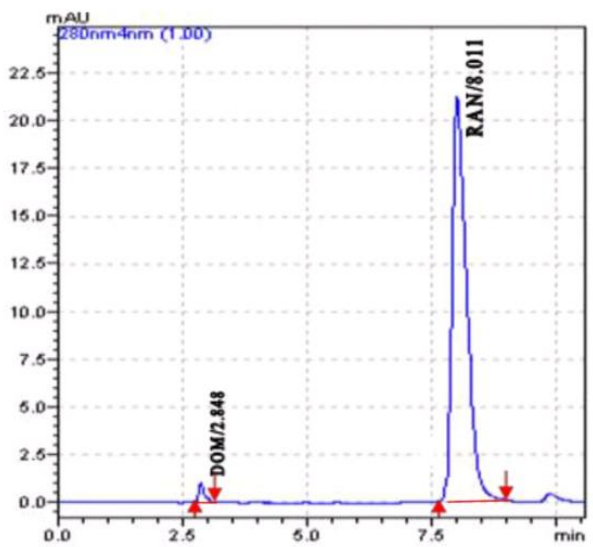

Fig. 4:- Chromatogram of Working Standard of Mixture of Domperidone (10 $\mu \mathrm{g} / \mathrm{ml})$ and Ranitidine Hydrochloride $(100 \mu \mathrm{g} / \mathrm{ml})$

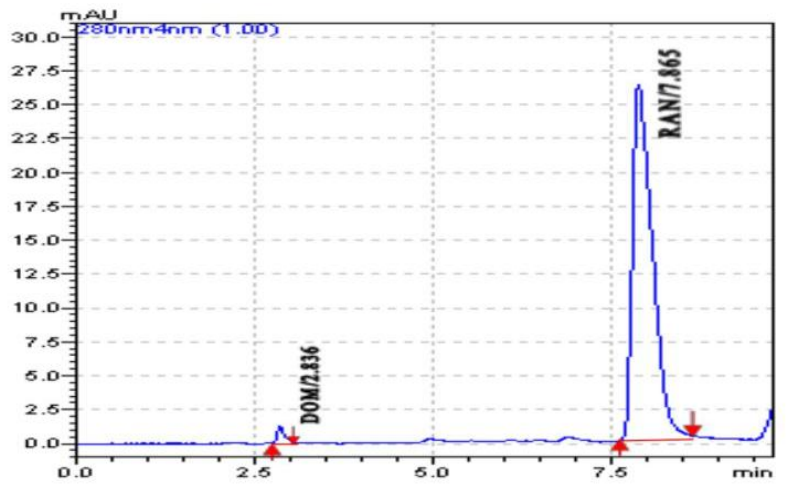

Fig. 5:- Chromatogram of Working Standard of Mixture of Domperidone $(15 \mu \mathrm{g} / \mathrm{ml})$ and Ranitidine Hydrochloride $(150 \mu \mathrm{g} / \mathrm{ml})$

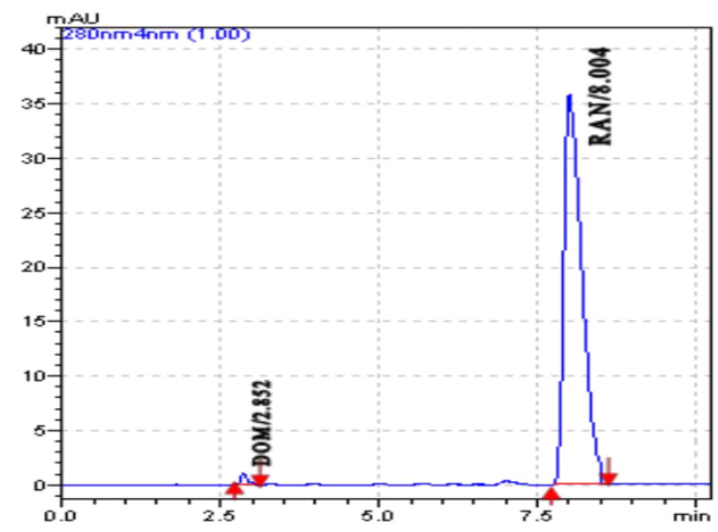

Fig. 6:- Chromatogram of Working Standard of Mixture of Domperidone $(20 \mu \mathrm{g} / \mathrm{ml})$ and Ranitidine Hydrochloride $(200 \mu \mathrm{g} / \mathrm{ml})$ 


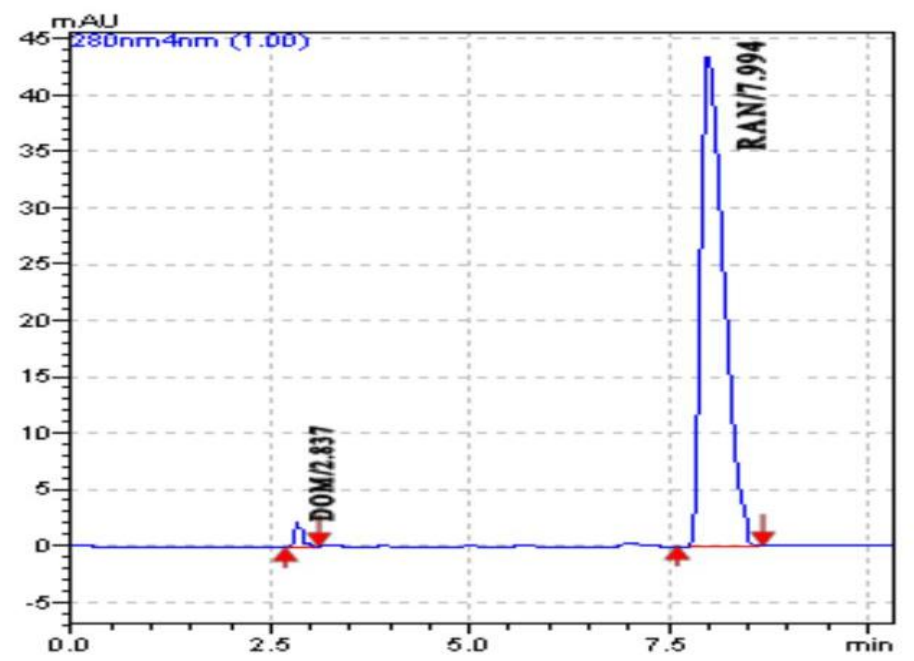

Fig.7:- Chromatogram of Working Standard of Mixture of Domperidone $(25 \mu \mathrm{g} / \mathrm{ml})$ and Ranitidine Hydrochloride $(250 \mu \mathrm{g} / \mathrm{ml})$

Table 1:- Calibration of Ranitidine Hydrochloride and Domperidone

\begin{tabular}{|c|c|c|c|c|}
\hline \multirow{2}{*}{ Sr. No. } & \multicolumn{2}{|c|}{ Conc. $(\boldsymbol{\mu g} / \mathbf{m l})$} & \multicolumn{2}{c|}{ Area $(\boldsymbol{\mu V}$.sec) } \\
\cline { 2 - 5 } & Ranitidine Hydrochloride & Domperidone & $\begin{array}{c}\text { Ranitidine } \\
\text { Hydrochloride }\end{array}$ & Domperidone \\
\hline $\mathbf{1}$ & 50 & 5 & 154560 & 2145 \\
\hline $\mathbf{2}$ & 100 & 10 & 312456 & 3945 \\
\hline $\mathbf{3}$ & 150 & 15 & 478963 & 5765 \\
\hline $\mathbf{4}$ & 200 & 20 & 624578 & 7463 \\
\hline $\mathbf{5}$ & 250 & 25 & 786452 & 9150 \\
\hline
\end{tabular}

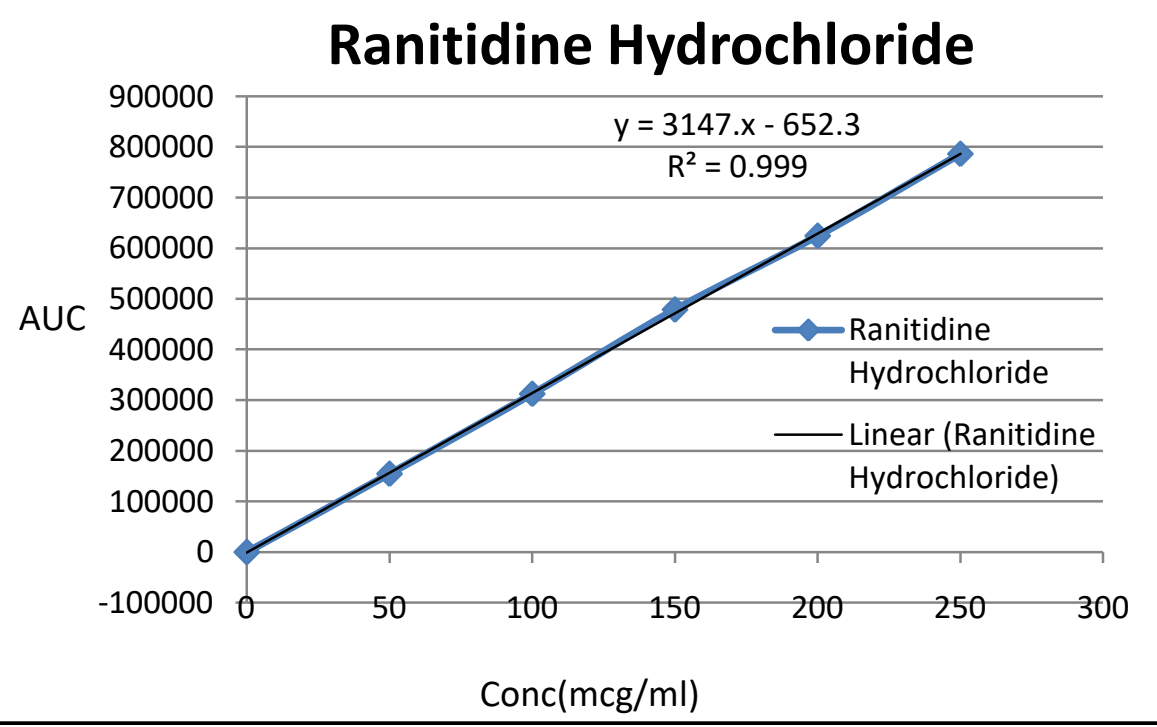

Fig. 8:- Calibration Curve of Ranitidine Hydrochloride 


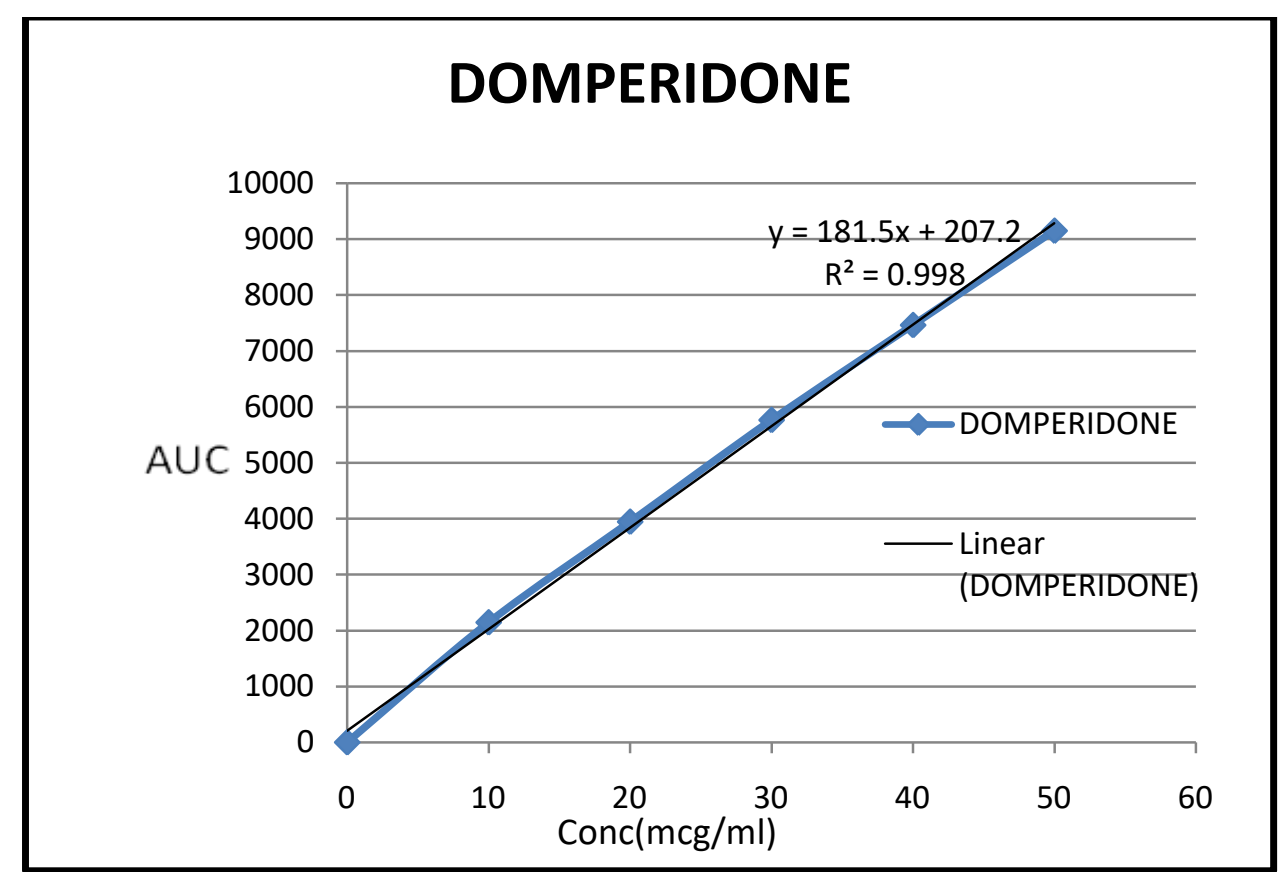

Fig.9:- Calibration Curve of Domperidone

\section{3) Selection of Mobile System -}

The pure drug of Ranitidine Hydrochloride and Domperidone were injected into HPLC system by using different solvent systems. Different mobile phases like acetonitrile: methanol: water, acetonitrile: methanol: potassium dihydrogen phosphate buffer, methanol: potassium dihydrogen phosphate buffer, methanol: water were tried in order to find the optimum conditions for the seperation of Ranitidine Hydrochloride and Domperidone. Finally the optimum composition of the mobile phase was selected as methanol $(55 \mathrm{ml})$ mixed with water $(45 \mathrm{ml})$, $\mathrm{pH}$ of water was adjusted to 3 by ortho- phosphoric acid which gave satisfactory results with sharp well defined and well resolved peaks and acceptable peak parameters as compared to other mobile phases.

\section{4) Preparation of Mobile Phase -}

Methanol $(55 \mathrm{ml})$ was mixed with water $(45 \mathrm{ml})$ and then $\mathrm{pH}$ of water was adjusted to 3 by addition of orthophosphoric acid.

\section{5) Degassing the Mobile Phase -}

The mobile phase prepared was degassed by ultrasonication for about $20 \mathrm{~min}$, so as to avoid the disturbances caused by dissolved gases.

\section{6) Filtration of Mobile Phase -}

The mobile phase after degassing was filtered through $0.45 \mu$ membrane nylon filter to remove the smaller particles that may be present in the mobile phase \& which may cause clogging of column.

\section{7) Preparation of Standard Stock Solutions -}

Take $50 \mathrm{mg}$ of Ranitidine Hydrochloride \& $50 \mathrm{mg}$ of Domperidone separately in $50 \mathrm{ml}$ volumetric flask which was then dissolved in $50 \mathrm{ml}$ mobile phase with shaking. Take $5 \mathrm{ml}$ from this solution and dilute it upto $50 \mathrm{ml}$ with mobile phase. This becomes stock solution of $100 \mu \mathrm{g} / \mathrm{ml}$. Then it was sonicated. From standard stock solution of drug, appropriate dilutions were made using the mobile phase \& the sample was filtered through $0.45 \mu \mathrm{m}$ of clear filtrate were injected into the HPLC column.

\section{8) Loading of Mobile Phase -}

Filtered \& degassed mobile phase was loaded in the reservoir. Priming was done for each freshly prepared mobile phase.

\section{9) Baseline Stabilization -}

The detector was turned on for an hour before the actual run in order to obtain the stable UV light. The mobile phase run was started at desired flow rate and the run was continued until the stable baseline was obtained.

10) Loading of Samples -

Well prepared \& filtered samples of Ranitidine Hydrochloride and Domperidone were loaded into the Rheodyne injector port using a syringe and the sample was then injected. 


\section{1) Washing the Column -}

Once the analysis of samples was finished, the column was first washed by flushing with the mobile phase for half an hour, afterwards with double distilled water \& methanol in 1:1 proportion for another one hour.

12) Selection \& Optimization of HPLC Method -

After the selection of suitable mobile phase, it was then optimized for its reproducibility, sensitivity and accuracy.

The optimized parameters for selected method are as below.

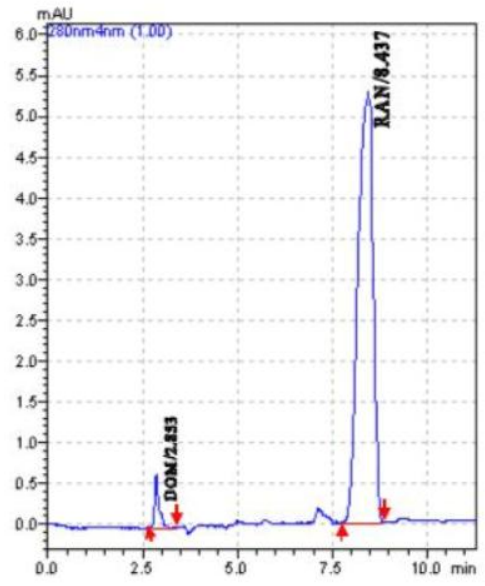

Fig. 10:- Chromatogram of Working Standard of $(10 \mu \mathrm{g} / \mathrm{ml})$ Domperidone and Ranitidine Hydrochloride $(150 \mu \mathrm{g} / \mathrm{ml})$

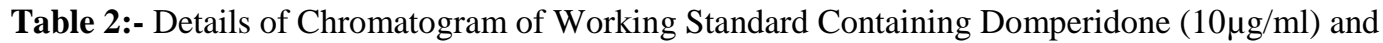
Ranitidine Hydrochloride $(150 \mu \mathrm{g} / \mathrm{ml})$

\begin{tabular}{|c|c|c|c|c|c|c|c|}
\hline $\begin{array}{c}\text { Sr. } \\
\text { No. }\end{array}$ & Name of Drug & RT & $\begin{array}{c}\text { Area } \\
\mathbf{\%}\end{array}$ & $\begin{array}{c}\text { Area } \\
\mathbf{\%}\end{array}$ & $\begin{array}{c}\text { Tailing } \\
\text { Factor }\end{array}$ & $\begin{array}{c}\text { Theoretical } \\
\text { Plate }\end{array}$ & Resolution \\
\hline 1 & Domperidone & 2.853 & 5093 & 2.0139 & 1.744 & 3116.661 & - \\
\hline 2 & Ranitidine Hydrochloride & 8.437 & 247800 & 97.986 & 1.537 & 6762.905 & 7.437 \\
\hline
\end{tabular}

Analysis of Marketed Tablet Formulation:-

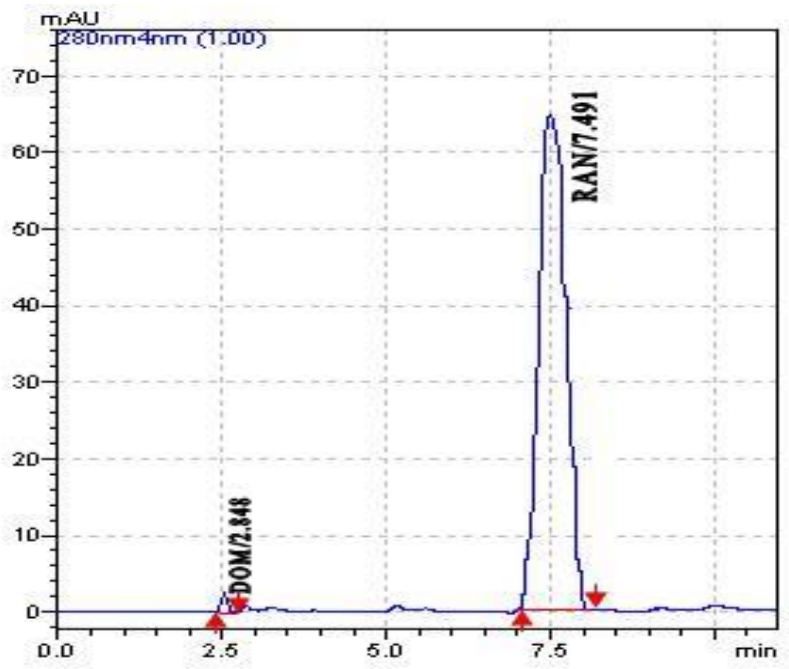

Fig. 11:- Chromatogram of Domperidone $(10 \mu \mathrm{g} / \mathrm{ml}) \&$ Ranitidine $(150 \mu \mathrm{g} / \mathrm{ml})$ ACITRO-D 
Table 3:- Details of Chromatogram of Ranitidine and Domperidone Tablet ACITRO-D

\begin{tabular}{|c|c|c|c|c|c|c|c|}
\hline $\begin{array}{c}\text { Sr. } \\
\text { No. }\end{array}$ & $\begin{array}{c}\text { Name of } \\
\text { Drug }\end{array}$ & RT & $\begin{array}{c}\text { Area } \\
\mathbf{\%}\end{array}$ & $\begin{array}{c}\text { Area } \\
\text { \% }\end{array}$ & $\begin{array}{c}\text { Tailing } \\
\text { Factor }\end{array}$ & $\begin{array}{c}\text { Theoretical } \\
\text { Plate }\end{array}$ & Resolution \\
\hline $\mathbf{1}$ & Domperidone & 2.848 & 5406 & 0.1690 & 1.932 & 3930.055 & - \\
\hline $\mathbf{2}$ & $\begin{array}{c}\text { Ranitidine } \\
\text { Hydrochloride }\end{array}$ & 7.491 & 3193329 & 99.8310 & 1.077 & 4565.157 & 5.860 \\
\hline
\end{tabular}

Table 4:- Analysis of ACITRO-D

\begin{tabular}{|c|c|c|c|c|c|c|}
\hline \multirow{2}{*}{$\begin{array}{c}\text { Sr. } \\
\text { No. }\end{array}$} & \multicolumn{2}{|c|}{ Amount Present in(mg) } & \multicolumn{2}{c|}{ Amount Found in(mg) } & \multicolumn{2}{c|}{ \%abel Claim } \\
\cline { 2 - 7 } & $\begin{array}{c}\text { Ranitidine } \\
\text { HCL }\end{array}$ & Domperidone & $\begin{array}{c}\text { Ranitidine } \\
\text { HCL }\end{array}$ & Domperidone & $\begin{array}{c}\text { Ranitidine } \\
\text { HCL }\end{array}$ & Domperidone \\
\hline $\mathbf{1}$ & 150 & 10 & 149.2 & 9.8 & 99.46 & 98.00 \\
\hline $\mathbf{2}$ & 150 & 10 & 149.4 & 9.6 & 99.66 & 96.00 \\
\hline $\mathbf{3}$ & 150 & 10 & 149.3 & 9.5 & 99.53 & 95.00 \\
\hline $\mathbf{4}$ & 150 & 10 & 149.6 & 9.7 & 99.73 & 97.00 \\
\hline $\mathbf{5}$ & 150 & 10 & 149.5 & 9.9 & 99.67 & 99.00 \\
\hline
\end{tabular}

Evaluation of Analytical Method (Method Validation):-

Linearity and Sensitivity -

Suitable dilutions of different concentrations using mobile phase were made from the standard stock solutions. The linearity of the relationship between peak area and concentration was determined by analyzing five working standards over the concentration range $50-250 \mu \mathrm{g} / \mathrm{ml}$ for Ranitidine and 5-25 $\mu \mathrm{g} / \mathrm{ml}$ for Domperidone. Here the peak areas were recorded against concentration \& graph of concentration Vs peak area was plotted. Results obtained are shown in table below 5 and 6.

Table 5:- Linearity of Ranitidine $(n=3)$

\begin{tabular}{|c|c|c|c|c|c|c|}
\hline Standard Conc. & $\mathbf{5 0} \boldsymbol{\mu g} / \mathbf{m l}$ & $\mathbf{1 0 0} \boldsymbol{\mu g} / \mathbf{m l}$ & $\mathbf{1 5 0} \boldsymbol{\mu g} / \mathbf{m l}$ & $\mathbf{2 0 0} \boldsymbol{\mu g} / \mathbf{m l}$ & $\mathbf{2 5 0} \boldsymbol{\mu g} / \mathbf{m l}$ \\
\hline Replicates & \multicolumn{5}{|c|}{ Peak area } \\
\hline $\mathbf{1}$ & 154560 & 312456 & 478963 & 624578 & 786452 \\
\hline $\mathbf{2}$ & 154559 & 312458 & 478965 & 624579 & 786456 \\
\hline $\mathbf{3}$ & 154557 & 312455 & 478962 & 624576 & 786453 \\
\hline Mean & 154558.7 & 312456.3 & 478963.3 & 624577.7 & 786453.7 \\
\hline $\mathbf{\text { SD }}$ & 1.527525 & 1.527525 & 1.527525 & 1.527525 & 2.08166 \\
\hline \%RSD & 0.000988 & 0.000489 & 0.000319 & 0.000245 & 0.000265 \\
\hline
\end{tabular}

Table 6:- Linearity of Domperidone $(n=3)$

\begin{tabular}{|c|c|c|c|c|c|}
\hline Standard Conc. & $\mathbf{5} \boldsymbol{\mu g} / \mathbf{m l}$ & $\mathbf{1 0} \boldsymbol{\mu g} / \mathbf{m l}$ & $\mathbf{1 5} \boldsymbol{\mu g} / \mathbf{m l}$ & $\mathbf{2 0} \boldsymbol{\mu g} / \mathbf{m l}$ & $\mathbf{2 5} \boldsymbol{\mu g} / \mathbf{m l}$ \\
\hline Replicates & \multicolumn{5}{|c|}{ Peak area } \\
\hline $\mathbf{1}$ & 2145 & 3945 & 5765 & 7463 & 9150 \\
\hline $\mathbf{2}$ & 2146 & 3947 & 5762 & 7462 & 9158 \\
\hline $\mathbf{3}$ & 2148 & 3942 & 5764 & 7460 & 9155 \\
\hline Mean & 2146.333 & 3944.667 & 5763.667 & 7461.667 & 9154.333 \\
\hline $\mathbf{\text { SD }}$ & 1.527525 & 2.516611 & 1.527525 & 1.527525 & 4.041452 \\
\hline \%RSD & 0.071169 & 0.063798 & 0.02605 & 0.020472 & 0.044148 \\
\hline
\end{tabular}

\section{Precision -}

Repeatability of method was established by analyzing various replicates standards of Ranitidine Hydrochloride and Domperidone. All the solutions were analyzed thrice, in order to record any intra-day and inter-day variation in the result. The result obtained for intra-day variations are shown in table no.7 and 8 and the result obtained for inter-day variations are shown in the table no. 9 and 10 . 
Table 7:- Intra-day Variability of Ranitidine Hydrochloride

\begin{tabular}{|c|c|c|c|c|c|c|}
\hline \multirow{2}{*}{$\begin{array}{c}\text { Conc. } \\
(\boldsymbol{\mu g} / \mathbf{m l})\end{array}$} & \multicolumn{2}{|c|}{ Peak area $(\boldsymbol{\mu V} \mathbf{s e c})$} & \multirow{2}{*}{ Mean area $(\boldsymbol{\mu V}$. sec $)$} & \multirow{2}{*}{ S SD } & \multirow{2}{*}{ RSD } \\
\cline { 2 - 4 } & Trial 1 & Trial 2 & Trial 3 & 154558.7 & 1.527525 & 0.000988 \\
\hline $\mathbf{5 0}$ & 154560 & 154559 & 154557 & 312456.3 & 1.527525 & 0.000489 \\
\hline $\mathbf{1 0 0}$ & 312456 & 312458 & 312455 & 478963.3 & 1.527525 & 0.000319 \\
\hline
\end{tabular}

Table 8:- Intra-day Variability of Domperidone

\begin{tabular}{|c|c|c|c|c|c|c|}
\hline \multirow{2}{*}{$\begin{array}{c}\text { Conc. } \\
(\mu \mathrm{g} / \mathrm{ml})\end{array}$} & \multicolumn{3}{|c|}{ Peak area $(\mu \mathrm{V} . \mathrm{sec})$} & \multirow{2}{*}{ Mean area $(\mu V$. sec $)$} & \multirow{2}{*}{ \pm SD } & \multirow{2}{*}{$\%$ RSD } \\
\hline & Trial 1 & Trial 2 & Trial 3 & & & \\
\hline 5 & 2149 & 2146 & 2148 & 2146.333 & 1.527525 & 0.071169 \\
\hline 10 & 3945 & 3947 & 3942 & 3944.667 & 2.516611 & 0.063798 \\
\hline 15 & 5765 & 5762 & 5764 & 5763.667 & 1.527525 & 0.026503 \\
\hline
\end{tabular}

Table 9:- Inter-day variability of Ranitidine Hydrochloride

\begin{tabular}{|c|c|c|c|c|c|c|}
\hline \multirow{2}{*}{$\begin{array}{c}\text { Conc. } \\
(\boldsymbol{\mu g} / \mathbf{m l})\end{array}$} & \multicolumn{2}{|c|}{ Peak area $(\boldsymbol{\mu V} \mathbf{s e c})$} & \multirow{2}{*}{ Mean area $(\boldsymbol{\mu V}$. sec $)$} & \multirow{2}{*}{ SD } & \multirow{2}{*}{ RSD } \\
\cline { 2 - 4 } & Day 1 & Day 2 & Day 3 & 176427.7 & 2.516611 & 0.001426 \\
\hline $\mathbf{5 0}$ & 176425 & 176428 & 176430 & 324567.7 & 1.527525 & 0.000471 \\
\hline $\mathbf{1 0 0}$ & 324568 & 324566 & 324569 & 489024.7 & 1.527525 & 0.000312 \\
\hline $\mathbf{1 5 0}$ & 489023 & 489025 & 489026 & & 4 & \\
\hline
\end{tabular}

Table 10:- Inter-day Variability of Domperidone

\begin{tabular}{|c|c|c|c|c|c|c|}
\hline \multirow{2}{*}{$\begin{array}{c}\text { Conc. } \\
(\boldsymbol{\mu g} / \mathbf{m l})\end{array}$} & \multicolumn{2}{|c|}{ Peak area $(\boldsymbol{\mu V}$. sec $)$} & \multirow{2}{*}{ Mean area $(\boldsymbol{\mu V} . \mathbf{s e c})$} & \multirow{2}{*}{ S SD } & \multirow{2}{*}{ RSD } \\
\cline { 2 - 4 } & Day 1 & Day 2 & Day 3 & 3250.333 & 5.5075 & 0.169446 \\
\hline $\mathbf{5}$ & 3250 & 3256 & 3245 & 5024 & 4 & 0.079618 \\
\hline $\mathbf{1 0}$ & 5028 & 5020 & 5024 & 6023 & 2.6457 & 0.043927 \\
\hline $\mathbf{1 5}$ & 6020 & 6025 & 6024 & &
\end{tabular}

\section{Accuracy -}

To check the accuracy of proposed method, level of recovery carried out at 80,100 and $120 \%$ of the concentration as per standard addition method.

Here the product was accessed by addition of series of known amount of standard drug in the product and then the contents were estimated by assay method. The \% recovery for Ranitidine Hydrochloride and Domperidone is in the range.

Table 11:- Recovery Studies of Tablet Sample

\begin{tabular}{|c|c|c|c|c|c|c|c|c|c|}
\hline \multirow{2}{*}{$\begin{array}{l}\text { Tablet } \\
\text { Sample }\end{array}$} & \multirow{2}{*}{$\begin{array}{c}\begin{array}{c}\text { Level of } \\
\text { Recovery }\end{array} \\
\text { Drug }\end{array}$} & \multicolumn{2}{|c|}{$\begin{array}{l}\text { Amount of Sample } \\
\text { Drug Taken }(\mu \mathrm{g} / \mathrm{ml})\end{array}$} & \multicolumn{2}{|c|}{$\begin{array}{l}\text { Amount of Standard } \\
\text { Drug Added }(\mu \mathrm{g} / \mathrm{ml})\end{array}$} & \multicolumn{2}{|c|}{$\begin{array}{c}\text { Total Amount } \\
\text { Recovered }(\mu \mathrm{g} / \mathrm{ml})\end{array}$} & \multicolumn{2}{|c|}{\begin{tabular}{|l|}
$\%$ \\
Recovery \\
\end{tabular}} \\
\hline & & $\begin{array}{c}\text { Ranitidine } \\
\mathrm{HCl}\end{array}$ & $\begin{array}{c}\text { Domperi- } \\
\text { done }\end{array}$ & $\begin{array}{l}\text { Ranitidine } \\
\mathrm{HCl}\end{array}$ & $\begin{array}{c}\text { Domperi- } \\
\text { done }\end{array}$ & $\begin{array}{c}\text { Ranitidine } \\
\mathrm{HCl}\end{array}$ & $\begin{array}{l}\text { Domperi- } \\
\text { done }\end{array}$ & $\begin{array}{c}\text { Ranitidine } \\
\mathrm{HCl}\end{array}$ & $\begin{array}{l}\text { Domperi- } \\
\text { done }\end{array}$ \\
\hline \multirow{9}{*}{$\begin{array}{l}\text { ACITRO- } \\
\text { D }\end{array}$} & 80 & 150 & 10 & 120 & 8 & 269.50 & 17.90 & 99.80 & 99.44 \\
\hline & 80 & 150 & 10 & 120 & 8 & 269.52 & 17.50 & 99.80 & 97.22 \\
\hline & 80 & 150 & 10 & 120 & 8 & 269.56 & 17.60 & 99.82 & 97.77 \\
\hline & 100 & 150 & 10 & 150 & 10 & 299.50 & 19.60 & 99.83 & 98.00 \\
\hline & 100 & 150 & 10 & 150 & 10 & 299.65 & 19.80 & 99.88 & 99.00 \\
\hline & 100 & 150 & 10 & 150 & 10 & 299.58 & 19.40 & 99.85 & 97.00 \\
\hline & 120 & 150 & 10 & 180 & 12 & 329.50 & 21.60 & 99.85 & 98.18 \\
\hline & 120 & 150 & 10 & 180 & 12 & 329.55 & 21.40 & 99.87 & 97.27 \\
\hline & 120 & 150 & 10 & 180 & 12 & 329.58 & 21.80 & 99.88 & 99.09 \\
\hline
\end{tabular}


Table 12:- Statistical Validation of ACITRO-D Tablet Sample

\begin{tabular}{|c|c|c|c|c|c|c|}
\hline \multirow[b]{2}{*}{$\begin{array}{l}\text { Level of \% } \\
\text { Recovered }\end{array}$} & \multicolumn{2}{|c|}{$\%$ Mean } & \multicolumn{2}{|c|}{ \pm SD } & \multicolumn{2}{|c|}{ Standard Error of Mean } \\
\hline & $\begin{array}{c}\text { Ranitidine } \\
\mathrm{HCl}\end{array}$ & Domperidone & $\begin{array}{c}\text { Ranitidine } \\
\mathrm{HCl}\end{array}$ & Domperidone & $\begin{array}{c}\text { Ranitidine } \\
\mathrm{HCl}\end{array}$ & Domperidone \\
\hline 80 & 99.80 & 98.14 & 0.01 & 0.94 & 0.01 & 0.66 \\
\hline 100 & 99.85 & 98.00 & 0.02 & 0.82 & 0.01 & 0.58 \\
\hline 120 & 99.86 & 98.18 & 0.01 & 0.74 & 0.01 & 0.52 \\
\hline
\end{tabular}

\section{Limit of Detection (LOD) -}

LOD is calculated from the formula-

$\mathrm{LOD}=3.3 \sigma / \mathrm{S}$

$\sigma=$ Standard deviation of the response, $\mathrm{S}=$ Slope of the calibration curve from data

Ranitidine $\mathrm{HCl}: 0.00033 \mu \mathrm{g} / \mathrm{ml}$, Domperidone: $0.02864 \mu \mathrm{g} / \mathrm{ml}$.

\section{Limit of Quantitation (LOQ) -}

LOQ is calculated from the formula-

$\mathrm{LOQ}=10 \sigma / \mathrm{S}$

$\sigma=$ Standard deviation of the response, $S=$ Slope of the calibration curve from data

Ranitidine HCl: $0.001 \mu \mathrm{g} / \mathrm{ml}$, Domperidone: $0.0868 \mu \mathrm{g} / \mathrm{ml}$.

\section{Robustness -}

Robustness of the method was determined by carrying out the analysis under conditions during which mobile phase ratio and $\mathrm{pH}$ was altered. Variation of mobile phase $\mathrm{pH}$ and ratio were seemed to have greater impact on resolution and hence it should be meticulously controlled.

\section{Range -}

The range shown is given as follows:

Ranitidine $\mathrm{HCl}: 10-50 \mu \mathrm{g} / \mathrm{ml}$

Domperidone: $10-50 \mu \mathrm{g} / \mathrm{ml}$.

\section{Result and Discussion:-}

RP-HPLC method was developed and validated for estimation of Ranitidine Hydrochloride and Domperidone from bulk drug and tablet formulation. Method was validated by using different parameters likes linearity, precision, accuracy, limit of detection, limit of quantitation, specificity, range and robustness.

Table 13:- Optimized Parameters for HPLC Method

\begin{tabular}{|l|l|}
\hline Parameters & Chromatographic Conditions \\
\hline HPLC System & Schimadzu UFLC \\
\hline Pump & LC- 20 AD \\
\hline Detector & SPD M-20 A, PDA detector \\
\hline Column & $\begin{array}{l}\text { Thermo Scientific, BDS HYPERSIL } \\
\mathrm{C}_{18}(250 \mathrm{X} 4.6 \mathrm{~mm} \text { id,5 } \mu \text { particle size })\end{array}$ \\
\hline Column temperature & Ambient \\
\hline Mobile phase & Methanol:Water $(55: 45 \mathrm{v} / \mathrm{v})$ \\
\hline Concentration of standard solution & $\begin{array}{l}150 \mu \mathrm{g} / \mathrm{ml} \text { of Ranitidine Hydrochloride and } 10 \mu \mathrm{g} / \mathrm{ml} \text { of Domperidone in mobile } \\
\text { phase }\end{array}$ \\
\hline Detection of wavelength & $280 \mathrm{~nm}$ \\
\hline Flow rate & $1 \mathrm{ml} / \mathrm{min}$ \\
\hline Sample volume & $20 \mu \mathrm{l}$ \\
\hline Run time & $10 \mathrm{~min}$ \\
\hline Retention time & Ranitidine Hydrochloride: $7.865 \mathrm{~min}$, Domperidone: $2.836 \mathrm{~min}$. \\
\hline & \\
\hline
\end{tabular}


Method of RP High performance liquid chromatography has been successfully employed for simultaneous estimation of Ranitidine Hydrochloride and Domperidone from tablet dosage form. Method was validated as per ICH guidelines by using different parameters like linearity, precision, accuracy, limit of detection, limit of quantitation, specificity, range and robustness.

The linearity of Ranitidine Hydrochloride was observed in the range of $50-250 \mu \mathrm{g} / \mathrm{ml}$ and that of Domperidone was in the range of $5-25 \mu \mathrm{g} / \mathrm{ml}$. Detection wavelength used was $280 \mathrm{~nm}$ with correlation coefficient 0.9998 and 0.9951 for Ranitidine Hydrochloride and Domperidone respectively. The limit of detection was found to be $0.00033 \mu \mathrm{g} / \mathrm{ml}$ and $0.02864 \mu \mathrm{g} / \mathrm{ml}$ for Ranitidine Hydrochloride and Domperidone respectively \& limit of quatitation $0.001 \mu \mathrm{g} / \mathrm{ml}$ and $0.0868 \mu \mathrm{g} / \mathrm{ml}$ for Ranitidine Hydrochloride and Domperidone respectively. The percent relative standard deviation and high percent recovery data were satisfactory and confirms accuracy, precision and reliability of the method.

Thus the method is simple, accurate, precise, economical and reproducible for routine estimation of Ranitidine Hydrochloride and Domperidone respectively from tablet formulations.

\section{Conclusion:-}

Attempts were made to develop RP-HPLC method for simultaneous estimation of Ranitidine Hydrochloride and Domperidone from tablet formulation. RP-HPLC method was developed and validated as per ICH guidelines by using Methanol:Water (55:45 v/v) pH 3 as mobile phase. Retention time of Ranitidine Hydrochloride and Domperidone were found to be $7.865 \mathrm{~min}$ and $2.836 \mathrm{~min}$ respectively. The wavelength used was $280 \mathrm{~nm}$ and flow rate was $1.0 \mathrm{ml} / \mathrm{min}$.

The method was found to be simple, accurate, precise, economical and reproducible. So the proposed method can be used for the routine quality control analysis of Ranitidine Hydrochloride and Domperidone in tablet formulations.

\section{Acknowledgement:-}

We extend our sincere thanks to Dr. Savita J. Tauro Principal, St. John Institute of Pharmacy \& Research, Palghar, Mumbai (MS), for critical review of manuscript.

\section{Declaration of Interest:-}

No conflicts of interest.

\section{References:-}

1. Willard HH, Merritt LL, Dean JA, Settle FA. Instrumental Methods of Analysis. CBS Publishers and Distributors; Delhi; 2001; 7: 513-537, 580-599.

2. Kar A. Pharmaceutical Drug Analysis. New age international Publishers; 2005; 2: $452-467$.

3. Becket AH, Stenlake JB. Practical pharmaceutical chemistry. CBS Publication; New Delhi 2001; 4(2): $157-167$.

4. Jeffery GH, Meendharm J, Denny CR. Vogel's Textbook of Quantitative Chemical Analysis; Adison Wesley Loongman Ltd; 2000; 5: 292-305.

5. Sethi PD. "HPLC-Quantitative analysis of pharmaceutical formulations", CBS publishers and Distributors; New Delhi; 2001:11.

6. Moffat AC, Osselton MD, Widdop B. Clarke's Analysis of Drugs and Poisons; K.M.Varghese Co, Mumbai; 2004; 1: 201-218.

7. Kromidas S. HPLC made to measure. A practical handbook for optimisation Wiley- VCH Verlag GmbH \& Co. KgaA; 2006: 1-22, 106.

8. Chatwal GR, Sham KA. Instrumental methods of chemical Analysis; Himalaya Publishing house; 2002; 5: 1-4, 2.624-2.632.

9. SCIMEDIA High- Performance Liquid Chromatography (HPLC).html.

10. http://www.chemistry .nmsu.edu

11. An Introduction to Analytical Method Development for Pharmaceutical Formulations; Pharma info_net.html (Rashim B Patel, Analytical methods development, and manufacture of pharmaceuticals.

12. Swadesh JK. HPLC Practical and Industrial Applications; CRC Press; 2001; 2: 8, 9, 22-25.

13. Sethi, P.D, HPLC Quantitative Analysis of Pharmaceutical Formulations; CBS Publishers and distributors; New Delhi; 2001: 58-67.

14. Christen G.D. Analytical Chemistry; fifth editition; John Wiley \& Sons; Inc.2001:505

15. Connors KA.A; Text Book of Pharmaceutical Analysis; John Wiley and Sons; 1982; 3: 373-395 
16. Skoog DA, Holler EJ, Nieman TA. Principles of Instrumental Analysis Thomson Asia Pvt. Ltd, Singapore; 1998; 5: 725-741.

17. Willard HH, Merritt LL, Dean JA, Settle FA. Jr., Instrumental Methods of analysis; seventh edition; CBS Publishers and Distributors;1986, 629.

18. Bernard, J.A.and Chavon, R., Modern Methods of Chemical Analysis; McGraw-Hill Publishing Co. Ltd London; 1985: 4

19. Sharma BK. Instrumental Methods of Chemical Analysis; Goel Publishing House, Meerut; 1997; 18: 3-10, 8187

20. Ahuja S, Rasmussen H, Overview of HPLC Method Development for Pharmaceuticals; Academic Press; 2007; 1(8): 441-457.

21. ICH Harmonized Tripartite Guideline, Validation of Analytical Procedure: Methodology Q2 (R2); 1994: 1-13.

22. Moffat AC, Osselton MD, Widdop B. Clarke's Analysis of Drugs and Poisons. K.M. Varghese Co, Mumbai; 2004: 1: 508-509.

23. Validation of Compendial Procedures, the United State Pharmacopoeia (USP30-NF25), National Publishing Philadelphia. Asian; 2007: 1225. 